ARTICLE

https://doi.org/10.1038/s41467-020-20205-0

\title{
Pyrinap ligands for enantioselective syntheses of amines
}

Qi Liu'1,2,4, Haibo Xu1,2,4, Yuling $\mathrm{Li}^{1}$, Yuan Yao ${ }^{3}$, Xue Zhang ${ }^{1}$, Yinlong Guo ${ }^{1}$ \& Shengming Ma (1) 1,3凶

Amines are a class of compounds of essential importance in organic synthesis, pharmaceuticals and agrochemicals. Due to the importance of chirality in many practical applications of amines, enantioselective syntheses of amines are of high current interest. Here, we wish to report the development of $\left(R, R_{a}\right)-N$-Nap-Pyrinap and $\left(R, S_{a}\right)-N$-Nap-Pyrinap ligands working with $\mathrm{CuBr}$ to catalyze the enantioselective $\mathrm{A}^{3}$-coupling of terminal alkynes, aldehydes, and amines affording optically active propargylic amines, which are platform molecules for the effective derivatization to different chiral amines. With a catalyst loading as low as $0.1 \mathrm{~mol} \%$ even in gram scale reactions, this protocol is applied to the late stage modification of some drug molecules with highly sensitive functionalities and the asymmetric synthesis of the tubulin polymerization inhibitor (S)-(-)-N-acetylcolchinol in four steps. Mechanistic studies reveal that, unlike reported catalysts, a monomeric copper(I) complex bearing a single chiral ligand is involved in the enantioselectivity-determining step.

\footnotetext{
${ }^{1}$ State Key Laboratory of Organometallic Chemistry, Shanghai Institute of Organic Chemistry, Chinese Academy of Sciences, 345 Lingling Lu, 200032 Shanghai, People's Republic of China. ${ }^{2}$ University of Chinese Academy of Sciences, 100049 Beijing, People's Republic of China. ${ }^{3}$ Research Center for Molecular Recognition and Synthesis, Department of Chemistry, Fudan University, 220 Handan Road, 200433 Shanghai, People's Republic of China. ${ }^{4}$ These

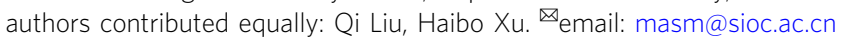


hiral amines have been not only used as resolving reagents, chiral ligands, and versatile building blocks in organic synthesis but also demonstrated wide applications in pharmaceuticals and agrochemicals (Fig. 1a) ${ }^{1-9}$. Thus, the development of highly efficient and enantioselective methods for syntheses of amines is of fundamental interest ${ }^{10,11}$. Due to the presence of a synthetically versatile carbon-carbon triple bond, propargylic amines are a very important class of compounds commonly used as precursors for other amines and diversified organic motifs. Consequently, attention has been paid to the synthesis of this type of compounds ${ }^{12-14}$. Enantioselective threecomponent coupling reaction of terminal alkynes, aldehydes, and amines provides one of the most straightforward approaches to propargylic amines due to the easy availability and diversity of the a<smiles>CCC[C@H]1CCCCN1</smiles><smiles>CN1CCCC1c1cccnc1</smiles>

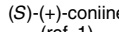<smiles>C#CCNC1CCc2ccccc21</smiles>

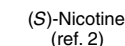<smiles>CC1(C#CC2CC2)NC(=O)Nc2ccc(C3CC3)cc21</smiles><smiles>COc1cc2c(cc1OC)[C@H]1CCCN1CC2</smiles>

$(R)-(+)-$-crispine $\mathrm{A}$ (ref. 3)<smiles>CCc1cccc(C)c1N(C(=O)CCl)[C@@H](C)COC</smiles>

(S)-metolachlor<smiles>C=CCCCOC(=O)C(CC)N(Cc1ccco1)C(=O)n1ccnc1</smiles><smiles>COc1cc2c(cc1OC)[C@H](C=CC1CCCCC1)N(C)CC2</smiles>

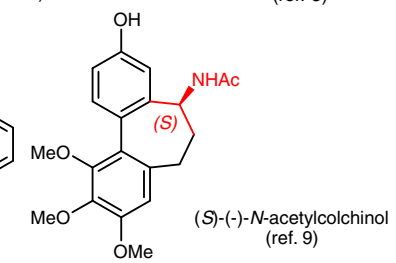

b

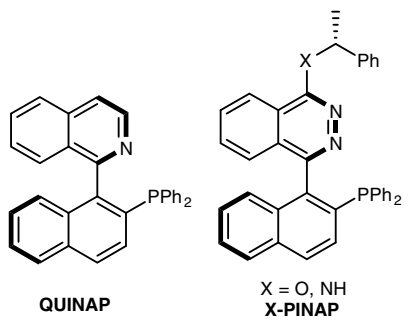<smiles></smiles><smiles>FC(F)(F)c1ccc2c(c1)C(c1ccccc1)N1Cc3ccccc3C2=N[C@H]1c1ccccc1</smiles><smiles>O=C(O)c1ccccc1C(=O)N[C@H]1CCCC[C@H]1NC(=S)Nc1cc(C(F)(F)F)c(Br)c(C(F)(F)F)c1</smiles>

Selected typical examples of challenging substrates:<smiles>CC#C[C](C=Cc1ccccc1)N(Br)CC</smiles><smiles>CCCCCC#CC#C[C@@H](C(C)C)N1CCC(=O)CC1</smiles><smiles>OCC#CC(Cl)N1CCCC1</smiles><smiles>CC(C)[C@H](C#CC(O)c1ccccc1)N(Cc1ccccc1)c1ccccc1</smiles><smiles>CC(C)(O)C#CC(c1ccccc1)N(Cc1ccccc1)c1ccccc1</smiles><smiles>C(#C[C@H](c1ccccc1)N1CCCCC1)c1ccccc1</smiles>
(ref. 22) $85 \%$ ee
(ref. 25) (ref. 42)

C $\equiv \mathrm{R}+\mathrm{R}^{2} \mathrm{CHO}+\mathrm{R}^{3} \mathrm{~N}^{-\mathrm{R}^{4}} \stackrel{\text { cat. CuBr/Pyrinap }}{\longrightarrow}$<smiles>C#CC=NN</smiles>

Challenges:

(1) Lack of a powerful catalytic system that could be applied to broad spectrum of substrate combinations. (2) Highly efficient catalytic systems.<smiles>c1ccc(-c2c(-c3ccccc3)c(-c3ccccc3)c3ccccc3c2-c2ccccc2)cc1</smiles>

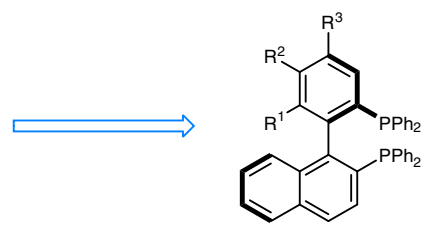

$R^{1}=$ MeO, $R^{2}, R^{3}=$ H MeO-NAPhePHOS $R^{1}, R^{2}, R^{3}=$ Me TriMe-NAPhePHOS

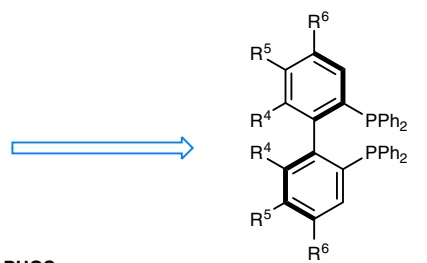

$\mathrm{R}^{4}=\mathrm{MeO}, \mathrm{R}^{5}, \mathrm{R}^{6}=\mathrm{H}$ MeO-BIPHEP $\mathrm{R}^{4}, \mathrm{R}^{5}=-\mathrm{OCH}_{2} \mathrm{O}-, \mathrm{R}^{6}=\mathrm{H}$ SEGPHOS

$R^{4}, R^{6}=\mathrm{MeO}, \mathrm{R}^{5}=\mathrm{H}$ Garphos

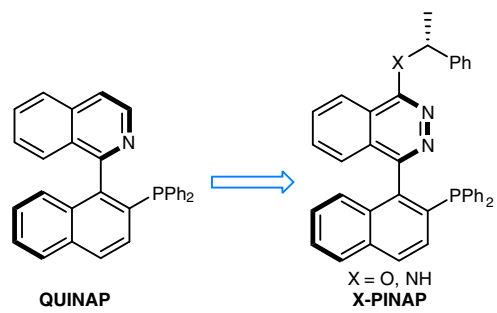

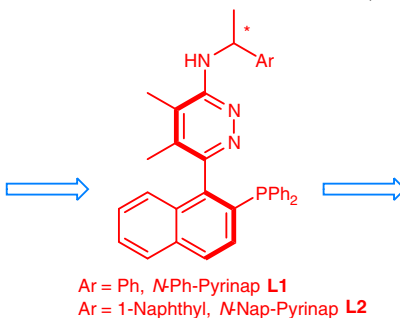<smiles>COc1cc(O[18O])cc(-c2ccccc2)c1-c1nnc(NC(C)c2ccccc2)c(C)c1C</smiles>

Fig. 1 Background and concept design. a Selected biologically active chiral amines. b Known ligands for catalytic enantioselective $A^{3}$-coupling reactions. c The method developed in this study. $\mathbf{d}$ Conceptual advance: evolution of binaphthyl to phenyl-naphthyl to biphenyl bisphosphines and the design of Pyrinap and Pyriphen. 
a Synthesis of $N$-Ph-Pyrinap L1 and $N$-Nap-Pyrinap L2

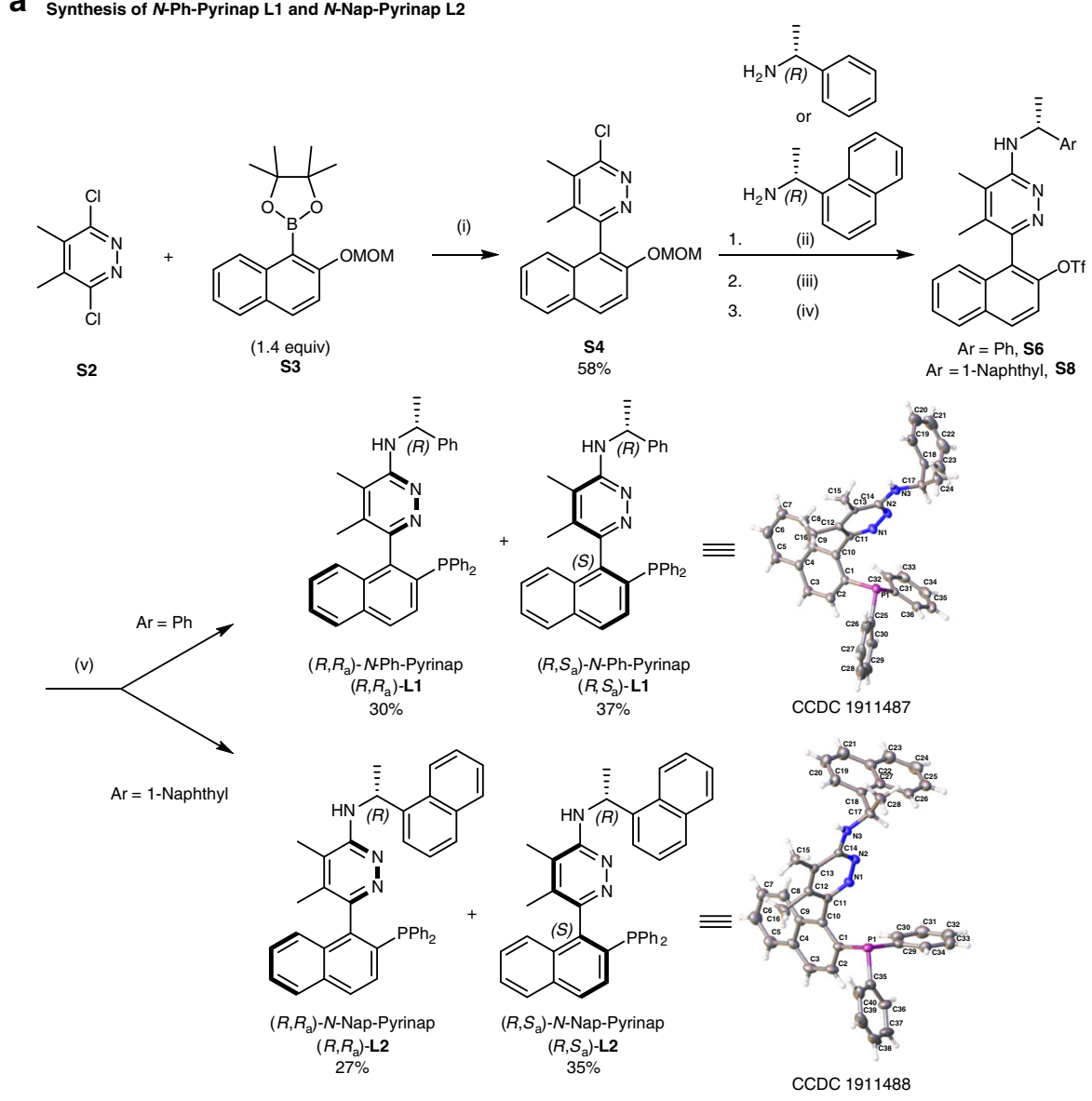

b Determination of the rotation barrier of $L 2$
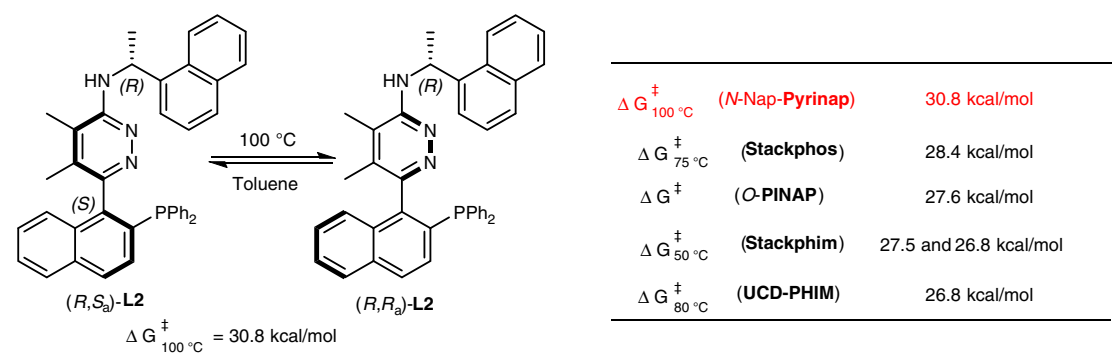

Fig. 2 Synthesis of Pyrinap ligands and determination of rotation barrier between $\left(\boldsymbol{R}_{\boldsymbol{r}} \boldsymbol{S}_{\boldsymbol{a}}\right)$-L2 and $\left(\boldsymbol{R}, \boldsymbol{R}_{\boldsymbol{a}}\right)$-L2. Reagents and conditions: (i) $\mathrm{Pd}(\mathrm{OAC})_{2}(5$ mol\%), $\mathrm{PPh}_{3}$ (20 mol\%), $\mathrm{Na}_{2} \mathrm{CO}_{3}$ (2 equiv), $\mathrm{DME} / \mathrm{H}_{2} \mathrm{O}=3: 1$, reflux, (58\%); (ii) ( $R$ )-1-phenylethyl amine or ( $R$ )-1-(1-naphthyl)ethyl amine (1.3 equiv), $\mathrm{Pd}$ $(\mathrm{OAc})_{2}$ (5 mol\%), rac-Binap (7.5 mol\%), $\mathrm{Cs}_{2} \mathrm{CO}_{3}$ (1.4 equiv), toluene, reflux; (iii) $\mathrm{HCl}\left(3 \mathrm{M}\right.$ in $\mathrm{MeOH} / \mathrm{H}_{2} \mathrm{O}$ ), r.t.; (iv) PhNTf 2 (1.0 equiv), Et $\mathrm{PH}_{3}$ (1.0 equiv), $\operatorname{DMAP}(10 \mathrm{~mol} \%), \mathrm{DCM}$, r.t. (for $\mathrm{Ar}=\mathrm{Ph}, 83 \%$ yield in step (ii) and $90 \%$ yield over 2 steps (iii and iv); for $\mathrm{Ar}=1$-naphthyl, $86 \%$ yield over 2 steps (ii and iii) and $90 \%$ yield in step (iv).) (v) $\mathrm{NiCl}_{2}$ (dppe) (10 mol\%), $\mathrm{HPPh}_{2}$ (2 equiv), DABCO (4 equiv), DMF, $120^{\circ} \mathrm{C}, 12 \mathrm{~h}$. DME 1,2-dimethoxyethane, DMAP 4-dimethylaminopyridine, DCM dichloromethane, DABCO triethylenediamine, DMF N,N-dimethylformamide.

three starting materials. Chiral ligands listed in Fig. 1b have been developed or applied for this reaction by Brown ${ }^{15}$, Knochel ${ }^{16-23}$, Carreira $^{24,25}$, Aponick ${ }^{26-28}, \mathrm{Naeimi}^{29}$, Seidel $^{30}$, and Guiry ${ }^{31,32}$. However, challenges still remain: (1) Lack of a powerful catalytic system that could be applied to broad spectrum of very challenging combinations for three types of substrates of terminal alkynes, aldehydes, and amines. (2) More practical and efficient catalytic systems are highly desirable. Developing ligands should be the solution.

It is well known that for atropisomeric diphosphine ligands the backbone skeletons greatly affect their catalytic performance in terms of both reactivity and enantioselectivity. For example, when binaphthyl ligand BINAP (2,2'-bis(diphenylphosphino)-1,1'binaphthyl) was replaced with the phenyl-naphthyl ligands
(MeO-NAPhePHOS and TriMe-NAPhePHOS) and biphenyl ligands (MeO-BIPHEP, SEGPHOS, and Garphos), some of the challenges in enantioselective hydrogenation reactions have been properly addressed ${ }^{33-39}$.

In this work, inspired by such backbone effect on catalytic activity and previous studies on axially chiral P,N ligands ${ }^{24,40}$, we report the development of the ligands phenyl-naphthyl-type ligand $\mathrm{N}$-Ph-Pyrinap L1, $\mathrm{N}$-Nap-Pyrinap L2, and the diphenyltype ligand $\mathbf{L} 3$ to address the challenges with respect to the scope of the combination of alkynes, aldehydes, and amines (Fig. 1d)

\section{Results}

Synthesis of Pyrinap ligands. At first, we tried to synthesize Pyriphen L3. But the transformation from triflate S1 to L3 could 
Table 1 Optimization of the reaction conditions.

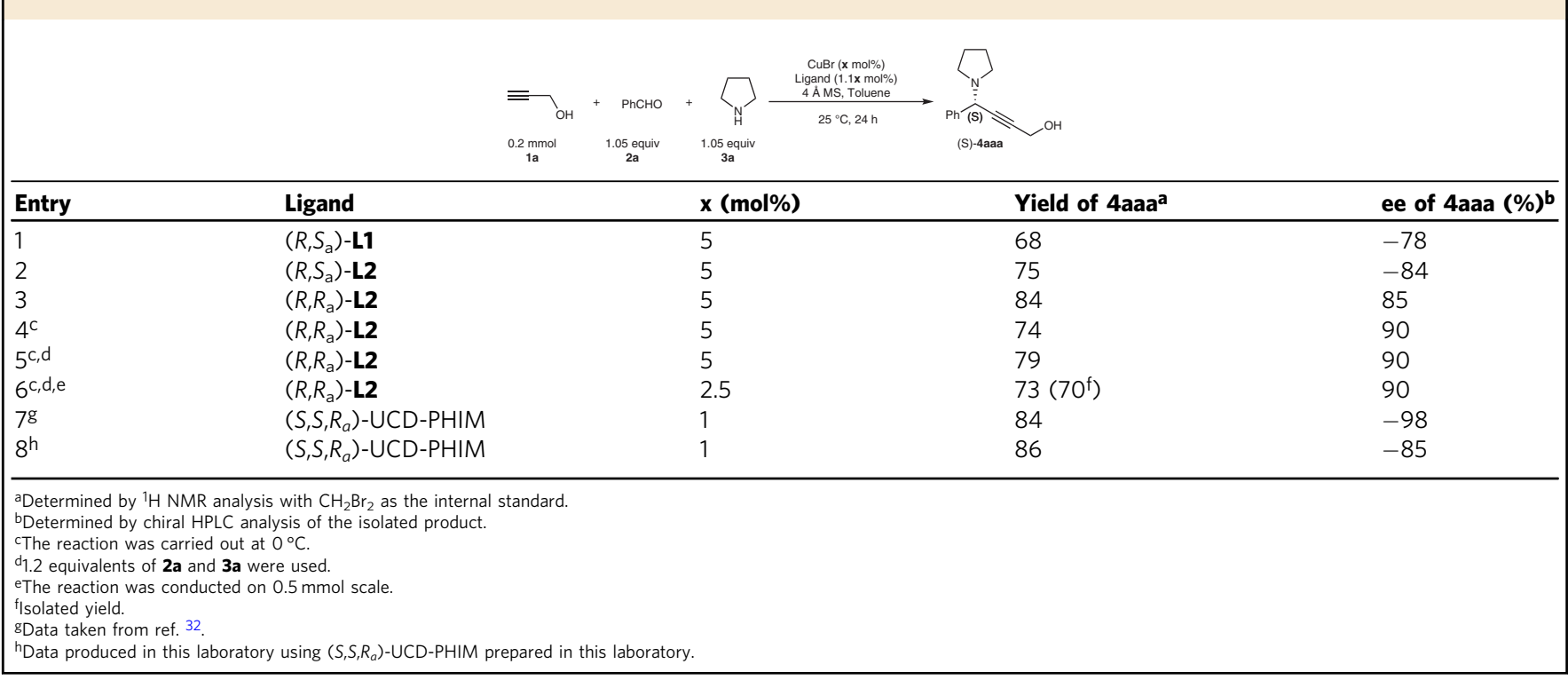

not be realized by the Ni-catalyzed phosphorylation reaction. The reaction gave only a complex mixture (see Supplementary information for the details). Subsequently, we turned our attention to synthesize $N$-Ph-Pyrinap L1 or N-Nap-Pyrinap L2. The synthesis of Pyrinap was successfully realized as shown in Fig. 2b: the Suzuki coupling reaction of 3,6-dichloro-4,5-dimethylpyridazine S2 with boronate $\mathbf{S 3}$ produced biaryl compound S4 in $58 \%$ yield. Subsequent amination reaction with $(R)$-1-phenylethyl amine or $(R)$-1-(1-naphthyl)ethyl amine, deprotection, and triflation afforded corresponding triflates $\mathbf{S 6}$ or S8, respectively. Finally, Ni-catalyzed coupling of $\mathbf{S 6}$ or $\mathbf{S 8}$ with $\mathrm{HPPh}_{2}$ provided a mixture of diastereomers of $\mathbf{L} \mathbf{1}$ or $\mathbf{L} \mathbf{2}$, respectively, which may be separated easily via column chromatography separation on silica gel. The absolute configurations of $\left(R, S_{\mathrm{a}}\right)-\mathbf{L} \mathbf{1}$ and $\left(R, S_{\mathrm{a}}\right)$ - $\mathbf{L} 2$ were firmly established by X-ray single-crystal analysis, respectively. ( $S$, $\left.R_{\mathrm{a}}\right)$ - $\mathbf{L} \mathbf{2}$ and $\left(S, S_{\mathrm{a}}\right)$ - $\mathbf{L} \mathbf{2}$ could also be easily prepared by the same synthetic procedure with $(S)$-1-(1-naphthyl)ethyl amine (see the Supplementary Fig. 3 for the details). In order to understand the nature of these ligands, we first determined the rotational barrier between $\left(\boldsymbol{R}, \boldsymbol{S}_{\boldsymbol{a}}\right)-\mathbf{L} \mathbf{2}$ and $\left(\boldsymbol{R}, \boldsymbol{R}_{\boldsymbol{a}}\right)-\mathbf{L} \mathbf{2}$ in toluene at $100{ }^{\circ} \mathrm{C}$ to be $30.8 \mathrm{kcal} / \mathrm{mol}$, which is higher than those for $O$-PINAP $(27.6 \mathrm{kcal} / \mathrm{mol})^{41}$, at $75^{\circ} \mathrm{C}$ for Stackphos $(28.4 \mathrm{kcal} / \mathrm{mol})^{26}$, at $50{ }^{\circ} \mathrm{C}$ for StackPhim $(26.8 \text { and } 27.5 \mathrm{kcal} / \mathrm{mol})^{28}$, and at $80^{\circ} \mathrm{C}$ for UCD-PHIM $(26.8 \mathrm{kcal} / \mathrm{mol})^{31}$ (Fig. 2b). Thus, the ligand $\mathbf{L} 2$ is configurationally more stable under ambient conditions.

Optimization of reaction conditions. With these two ligands in hand, we tried the enantioselective $\mathrm{A}^{3}$-coupling of the most challenging propargyl alcohol 1a with a much smaller steric hindrance, benzaldehyde $\mathbf{2 a}$, and pyrrolidine $\mathbf{3 a}$. After some screenings, it was observed that $\left(R, R_{\mathrm{a}}\right)-\mathbf{L} 2$ ligand gave the highest yield (84\%) and enantiomeric excess (ee) (85\%) at room temperature (r.t.) (Table 1, entries $1-3$ ). The reaction at $0{ }^{\circ} \mathrm{C}$ afforded the product in $90 \%$ ee (Table 1 , entry 4 ). When 1.2 equivalent (equiv) each of 2a and 3a were applied, the yield was improved (Table 1 , entry 5 ). The catalyst loading could be reduced to 2.5 mol\% with the same level of enantioselectivity (Table 1, entry 6). Following the same conditions reported in ref. ${ }^{32}$ (Table 1, entry $7),\left(S, S, R_{a}\right)$-UCD-PHIM provided the product in $86 \%$ yield with $-85 \%$ ee (Table 1 , entry 8 ).
Substrate scope. With the optimized reaction conditions in hand, we firstly tested the reactivity and enantioselectivity of various aromatic aldehydes 22,25 : in general, decent yields and over $90 \%$ ee were obtained regardless of the electronic properties of the phenyl groups and the position of substituents (Fig. 3a). A wide range of synthetically useful functional groups, such as halogen $(\mathbf{2 b}, \mathbf{2 j}, \mathbf{2} \mathbf{k}$, $\mathbf{2 l})$, alkoxy (2d, 2e), cyano (2g), ester (2h), trifluoromethyl group (2i), and chiral allene $(\mathbf{2 m})$ were intact under the optimal reaction conditions (products $(S)$-4aba, $(R)$-4aja, $(S)$-4aka, $(S)$-4ala, $(S)$ 4ada, $(S)$-4aea, $(S)$-4aga, $(S)$-4aha, $(S)$-4aia, and ( $\left.S, R_{\mathrm{a}}\right)$-4ama). Heteroaromatic aldehydes such as Ts-protected indolecarbaldehyde (2n), 2-benzo[b]thiophenecarbaldehyde (2o), and 2thiophenecarboxaldehyde $(2 \mathrm{p})$ all delivered the corresponding propargylic amines $(R)$-4ana, $(R)$-4aoa, and $(R)$-4apa with good yields and high ee. In addition, aliphatic aldehydes also reacted efficiently to afford the desired products $(S)$-4aqa and (S)-4ara in high ee.

The scope of terminal alkynes ${ }^{42}$ was subsequently examined (Fig. 3b): non-sterically hindered homopropargyl alcohol $\mathbf{1 b}$ could produce $(S)-4$ bsa in $96 \%$ yield with $90 \%$ ee. Even the reaction of $1^{\circ}$-alkyl-substituted terminal alkyne $1 \mathrm{c}$ without the hydroxyl group afforded the corresponding propargylic amine $(S)-4$ caa in $90 \%$ ee at $-5^{\circ} \mathrm{C}$. As for aryl-substituted alkyne 1d, high enantioselectivity was also obtained for the product $(S)-4 \mathbf{d a a}^{30}$. As expected, excellent yields and ee for products $(S)$-4eaa and $(S)$-4eqa were observed for tertiary propargylic alcohol 1e with aromatic aldehyde $\mathbf{2 a}$ or aliphatic aldehyde 2q.

Encouraged by the above results, we turned to explore the scope of amines (Fig. 3c) ${ }^{30}$ : a range of amines with different types of aldehydes and alkynes were tested (Fig. 3c). The ring size of 6to 8 -membered cyclic amines had no obvious effect on the enantiocontrol of the reaction (products $(S)-\mathbf{4 f a b},(S)-\mathbf{4 d a b},(S)$ 4aqb, $(S)$-4gac, and (S)-4had). For 4-piperidone 3e, which was used as an ammonia equivalent ${ }^{25}$, chiral $(S)$-4dte was obtained in $76 \%$ yield and $90 \%$ ee under a further modified conditions. Morpholine 3f could also furnish the product $(S)$-4iaf in $85 \%$ yield with $94 \%$ ee by using dimethyl carbonate instead of toluene as the solvent. Meanwhile, the reaction could be extended to acyclic amines with good yields and excellent ee for products $(S)$ $\mathbf{4 j a g}$ and $(S)-4 \mathbf{k a h}$. As we know that dibenzyl amine $\mathbf{3 i}$ is an 

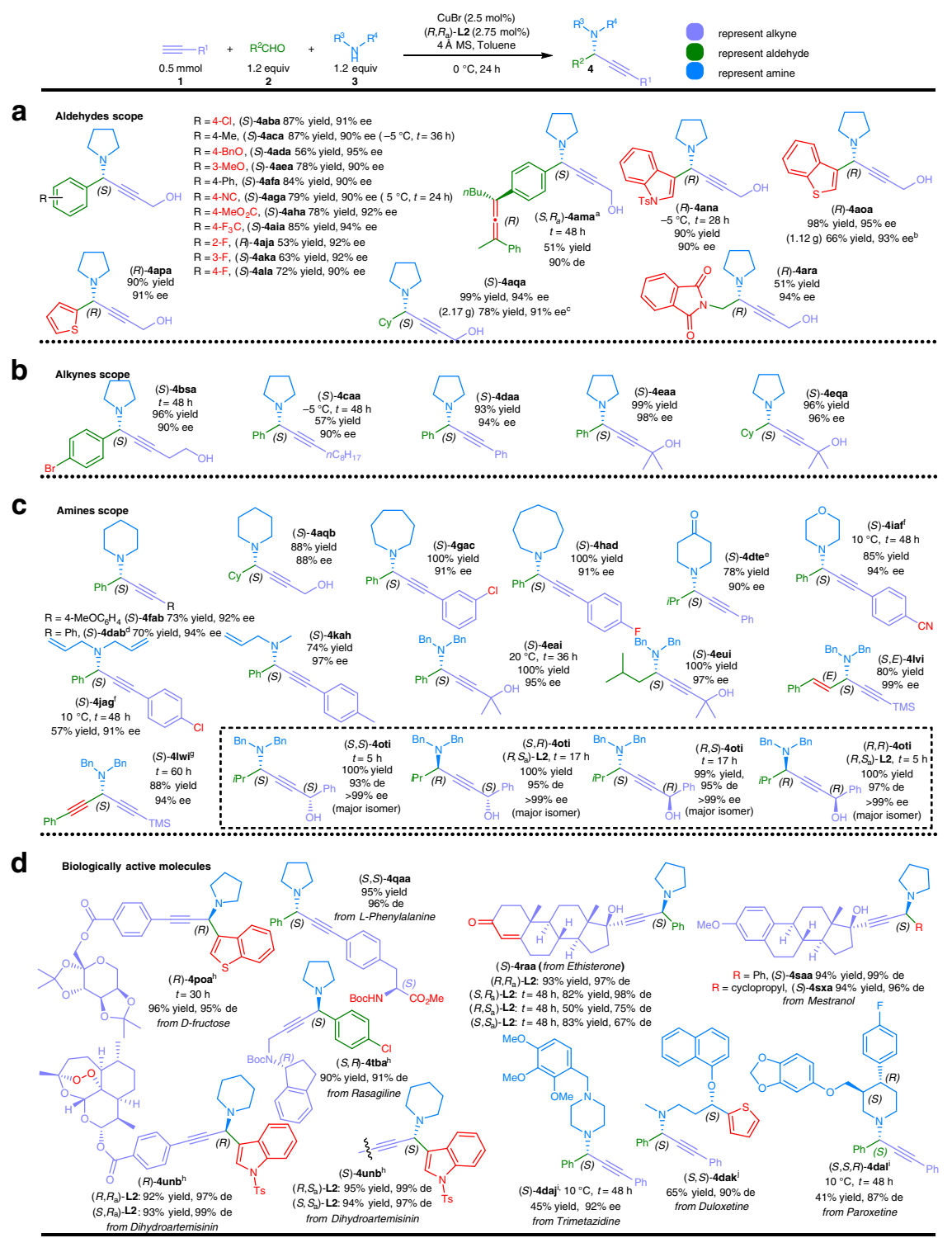

Fig. 3 Substrate scope of the enantioselective $\mathbf{A}^{\mathbf{3}}$-coupling reaction. a Aldehydes scope, $\mathbf{b}$ alkynes scope, $\mathbf{c}$ amines scope, and $\mathbf{d}$ biologically active molecules. Reaction conditions: athe reaction was carried out using $\mathbf{1 a}$ (1.2 equiv), $\mathbf{2} \mathbf{m}(0.15 \mathrm{mmol})$, and $\mathbf{3 a}$ ( 1.2 equiv). b The reaction was carried out using 1a (6.25 mmol), 20 (1.05 equiv), 3a (1.05 equiv), $\mathrm{CuBr}(0.1 \mathrm{~mol} \%),\left(R, R_{\mathrm{a}}\right)-\mathbf{L 2}(0.11 \mathrm{~mol} \%)$, and $4 \AA \mathrm{MS}(1.9 \mathrm{~g})$ in toluene $(16 \mathrm{~mL})$ at $0{ }^{\circ} \mathrm{C}$ for $4 \mathrm{~d}$. ${ }^{\mathrm{C}} \mathrm{The}$ reaction was carried out using $\mathbf{1 a}(12.5 \mathrm{mmol}), \mathbf{2 p}$ (1.05 equiv), 3a (1.05 equiv), CuBr $(0.1 \mathrm{~mol} \%),\left(R, R_{\mathrm{a}}\right)$ - $\mathbf{L 2}(0.11 \mathrm{~mol} \%)$, and $4 \AA \mathrm{MS}(1.9 \mathrm{~g})$ in toluene (31 $\mathrm{mL}$ ) at $0{ }^{\circ} \mathrm{C}$ for 2 days. ${ }^{\mathrm{d}}$ The reaction was carried out using $\mathbf{1 d}$ (1.2 equiv), $\mathbf{2 a}(0.5 \mathrm{mmol})$, and $\mathbf{3 b}$ ( 1.2 equiv). ${ }^{\mathrm{e}}$ The reaction was carried out using $\mathbf{1 d}(0.5$ mmol), 2t (2 equiv), 3e $\cdot \mathrm{HCl}$ (1.2 equiv), $\mathrm{NEt}_{3}$ (2.2 equiv), $\mathrm{CuBr}(2.5 \mathrm{~mol} \%),\left(R, R_{\mathrm{a}}\right)-\mathbf{L 2}(2.75 \mathrm{~mol} \%)$, and $4 \AA \mathrm{MS}(150.3 \mathrm{mg})$ in $\mathrm{DCM}(1.25 \mathrm{~mL})$ at $0{ }^{\circ} \mathrm{C}$ for $24 \mathrm{~h}$. fDMC (1.25 mL) was used as solvent. 8The reaction was carried out using trimethylsilylacetylene $\mathbf{1 l}$ (1.5 equiv), 3-phenylpropiolaldehyde $\mathbf{2} \mathbf{w}$ (0.5 mmol), 3i (1.0 equiv), $\mathrm{CuBr}(2.5 \mathrm{~mol} \%),\left(R, R_{\mathrm{a}}\right)-\mathbf{L 2}(2.75 \mathrm{~mol} \%)$, and $4 \AA \mathrm{MS}(150.6 \mathrm{mg})$ in DCM $(1.25 \mathrm{~mL})$ at $0{ }^{\circ} \mathrm{C}$ for $2.5 \mathrm{days} .{ }^{\mathrm{h}} \mathrm{The}$ reaction was carried out on a $0.25 \mathrm{mmol}$ scale. 'The reaction was carried out using $\mathbf{1}(0.5 \mathrm{mmol}), \mathbf{2}\left(1.2\right.$ equiv), $\mathbf{3} \cdot \mathrm{HCl}$ (1.2 equiv), and $\mathrm{NEt}_{3}(2.2 \mathrm{equiv})$ in DMC (1.25 mL). iThe reaction was carried out using $\mathbf{1}(0.5 \mathrm{mmol}), \mathbf{2}$ (1.2 equiv), 3. $\mathrm{HCl}$ (1.2 equiv), and $\mathrm{NEt}_{3}$ (2.2 equiv) in DCM (1.25 mL). The absolute configuration before the compound no. refers to the newly generated propargylic chiral center.

important amine due to the potential of debenzylation for further possible functionalization of the nitrogen atom. It should be noted that the known ligands for the reactions with dibenzyl amine $3 \mathbf{i}$ afforded $(S)$-4eai and (S,E)-4lvi in $49 \%$ yield with an ee of merely $32 \%$ and $96 \%$ yield with $82 \%$ ee, respectively ${ }^{22,32}$. Thus, the scope of this transformation with dibenzyl amine $3 \mathbf{i}$ was investigated: both aromatic and aliphatic aldehydes could achieve excellent yields and ee with tertiary propargylic alcohol 1e (products $(S)$-4eai and (S)-4eui). Even an alk-2-enal or 2-alkynal, which may readily undergo conjugate addition with the amine, worked with an excellent selectivity: cinnamaldehyde $E$ - 2v smoothly yielded the corresponding product $(S, E)-4 \mathbf{l v i}$ in $80 \%$ yield and $99 \%$ ee; the reaction of 3-phenylpropiolaldehyde 2w under standard conditions was very sluggish in toluene, producing $(S)$-4lwi in merely $6 \%$ nuclear magnetic resonance (NMR) yield. However, $88 \%$ yield and $94 \%$ ee of (S)-4lwi could be obtained by using dichloromethane (DCM) as solvent with 1.5 equiv of trimethylsilylacetylene $\mathbf{1 1}^{27}$. Importantly, all four different stereoisomers of 4oti may be obtained in excellent yields, ee, and diastereomeric excess (d.e.) by starting from optically active propargylic alcohol $(R)-10^{43}$ or $(S)-10^{43}$ and chiral ligand $\left(R, R_{\mathrm{a}}\right)-\mathbf{L} \mathbf{2}$ or $\left(R, S_{\mathrm{a}}\right)-\mathbf{L} \mathbf{2}$, respectively. 


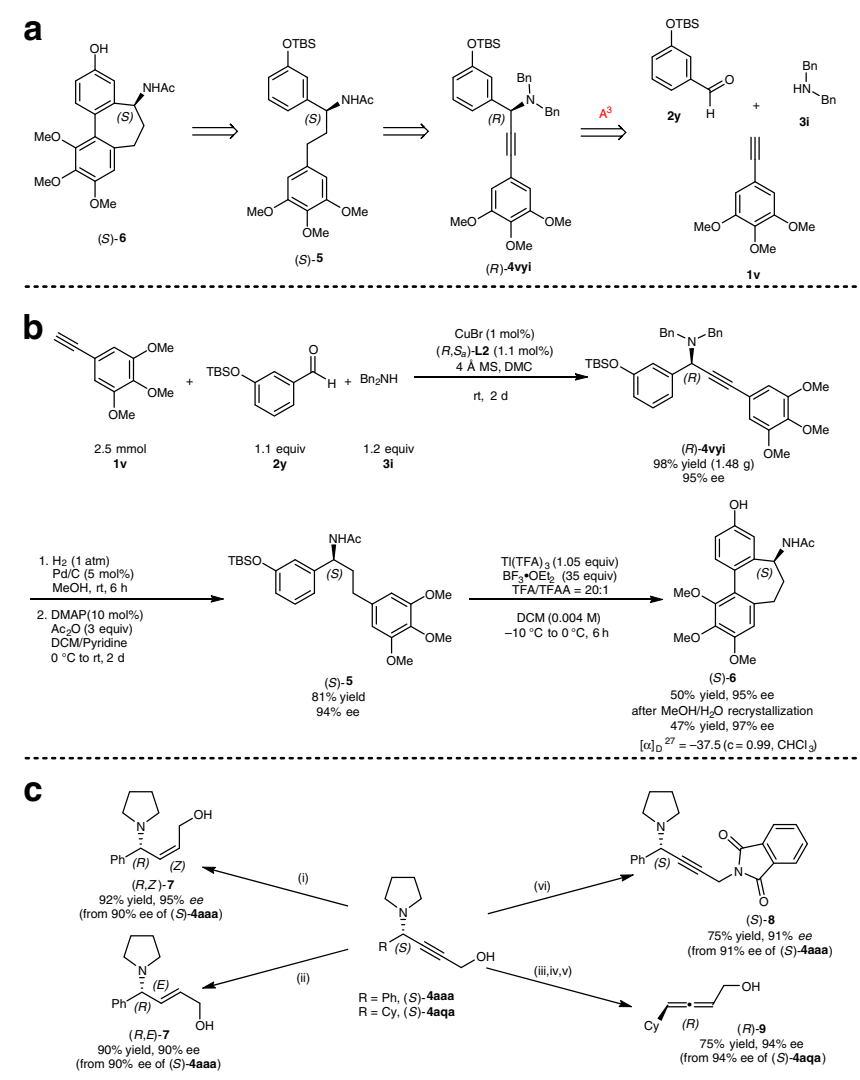

Fig. 4 Synthetic applications. a Retrosynthetic analysis of (S)-6. b A catalytic enantioselective synthesis of (S)-(-)- $N$-acetylcolchinol (S)-6.

c Transformation of propargylic amines (S)-4aaa and (S)-4aqa. Reagents and conditions: (i) $\mathrm{Ni}(\mathrm{OAc})_{2} \cdot 4 \mathrm{H}_{2} \mathrm{O}\left(1\right.$ equiv), $\mathrm{NaBH}_{4}(1$ equiv), ethylenediamine (3.5 equiv), $\mathrm{EtOH}, \mathrm{H}_{2}$ (1 atm), r.t., 3 h; (ii) $\mathrm{LiAlH}_{4}$ (2 equiv), $\mathrm{THF}, \mathrm{O}^{\circ} \mathrm{C}$ to r.t., 3 h; (iii) $\mathrm{TBSCl}$ (1.2 equiv), imidazole (2 equiv), $\mathrm{DCM}$, r.t., 12 h; (iv) $\mathrm{Znl} 2$ (50 mol\%), toluene, $110^{\circ} \mathrm{C}, 8 \mathrm{~h}$; (v) TBAF $3 \mathrm{H}_{2} \mathrm{O}$ (1 equiv), $\mathrm{THF}, 0^{\circ} \mathrm{C}$ to r.t., $12 \mathrm{~h}$; (vi) phthalimide ( 1 equiv), $\mathrm{DEAD}\left(1.1\right.$ equiv), $\mathrm{PPh}_{3}(1 \mathrm{equiv}), \mathrm{THF}^{\circ} \mathrm{O}^{\circ} \mathrm{C}$ to r.t., $12 \mathrm{~h}$. DCM dichloromethane, DEAD diethyl azodicarboxylate, DMAP 4-dimethylaminopyridine, DMC dimethyl carbonate, TBAF tetrabutylammonium fluoride, TBSCl tert-butyldimethylsilyl chloride, TFA trifluoroacetic acid, TFAA trifluoroacetic anhydride, THF tetrahydrofuran.

Having illustrated the broad substrate scope and efficient enantiocontrol ability of this catalytic system, late-stage modification of biologically active or drug molecules were further performed (Fig. 3d): alkynes derivatives of carbohydrate Dfructose $\mathbf{1 p}$ and amino acid L-phenylalanine $(S)-\mathbf{1} \mathbf{q}^{44}$ provided the corresponding products $(R)$-4poa and $(S, S)$-4qaa smoothly in high yields and d.e.; the terminal alkyne groups in commercial drugs, ethisterone 1r, mestranol 1s, and Boc-protected Rasagiline $(R)-\mathbf{1 t}^{45}$, may be readily converted to corresponding chiral propargylic amines $(S)$-4raa, $(S)$-4saa, $(S)$-4sxa, and $(S, R)$-4tba, without affecting other functionalities. For ethisterone 1r, cases of match and mismatch between the substrate chirality and the ligand chirality were observed: the reaction with $\left(R, R_{\mathrm{a}}\right)-\mathbf{L} 2$ or $(S$, $R_{\mathrm{a}}$ )-L2 yielded $(S)$-4raa in $93 \%$ yield with $97 \%$ d.e. or $82 \%$ yield with $98 \%$ d.e., respectively. As a comparison, with $\left(R, S_{\mathrm{a}}\right)-\mathbf{L} 2$ or $(S$, $S_{\mathrm{a}}$ )-L2, the same product was produced in $50 \%$ yield with $75 \% \mathrm{~d}$. e. or $83 \%$ yield with $67 \%$ d.e., respectively. The reaction of the terminal alkyne derivative of dihydroartemisinin, indole carboaldehyde, and piperidine afforded ( $R$ )-4unb and $(S)$-4unb successfully via the current protocol: even the fragile bridged peroxide group in the dihydroartemisinin, which plays an important role in antimalarial activity ${ }^{46}$, was tolerated. In this case, the absolute configuration of the newly formed propargylic chiral center was completely controlled by the axial chirality of the chiral ligand, regardless of the substrate chirality or the central chirality of the chiral ligand. This may be explained by the fact that the chirality in dihydroartemisinin is far away from the terminal $s p$ carbon atom. Moreover, amine-containing drug molecules, trimetazine (3j), duloretine $((S)-3 \mathbf{k})$, and paroxetine $((S, R)-3 \mathbf{l})$, could be used directly in this reaction to deliver products $(S)$-4daj, $(S, S)$-4dak, and $(S, S, R)$-4dal in high enantioselectivity under slightly modified conditions (Fig. $3 \mathrm{~d}$ ).

To demonstrate the practical utility, the reaction of simple propargyl alcohol 1a, cyclohexanecarbaldehyde 2q, and pyrrolidine 3a was performed on $12.5 \mathrm{mmol}$ scale with only $0.1 \mathrm{~mol} \%$ of $\mathrm{CuBr}$ and $0.11 \mathrm{~mol} \%$ of $\left(R, R_{\mathrm{a}}\right)$ - $\mathbf{L} 2$ affording chiral propargylic amine $(S)-\mathbf{4 a q a} \mathbf{a}^{42}$ in $78 \%$ yield $(2.17 \mathrm{~g})$ and $91 \%$ ee after a simply acid-base extraction. Heteroaromatic aldehyde 20 could also produce $1.12 \mathrm{~g}$ of $(R)-4$ aoa in $66 \%$ yield and $93 \%$ ee on 6.25 mmol scale with $0.1 \mathrm{~mol} \%$ of catalyst (Fig. 3a).

Synthetic applications. The colchicine degradation product $(S)$ $(-)-N$-acetylcolchinol $(S)-6$ is the tubulin polymerization inhibitor $^{47-49}$. Previously reported enantioselective synthesis of $(S)$-6 suffered from using stoichiometric amounts of chiral reagents and step-economy $9,50-58$. We reasoned that our methodology could be applied to the highly efficient enantioselective synthesis of $(S)-6$ as outlined in Fig. 4a. The key step would be the enantioselective $\mathrm{A}^{3}$ reaction with the abovementioned challenging dibenzyl amine $3 \mathbf{i}$ (Fig. 4b): at first, the enantioselective $\mathrm{A}^{3}$-coupling reaction of alkyne $\mathbf{1 v}$, aromatic aldehyde $\mathbf{2 y}$, and dibenzyl amine $\mathbf{3 i}$ under standard conditions at r.t. was very sluggish, affording the desired propargylic amine $(R)-4 v y i$ in $81 \%$ yield and $96 \%$ ee with $19 \%$ of $1 \mathbf{v}$ being recovered even after 7 days. Fortunately, this targeted transformation could be efficiently achieved at r.t. with $1.0 \mathrm{~mol} \%$ of $\mathrm{CuBr}$ and $1.1 \mathrm{~mol} \%$ of $\left(R, S_{\mathrm{a}}\right)-\mathbf{L} 2$ in dimethyl carbonate 
a

A linear relationship between ee of the ligand and the product
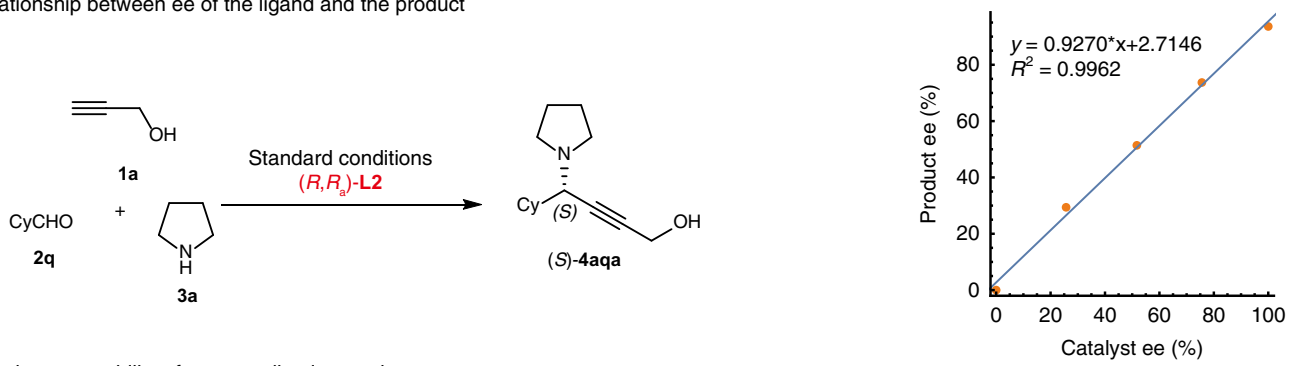

b DFT calculations on stability of two coordination modes
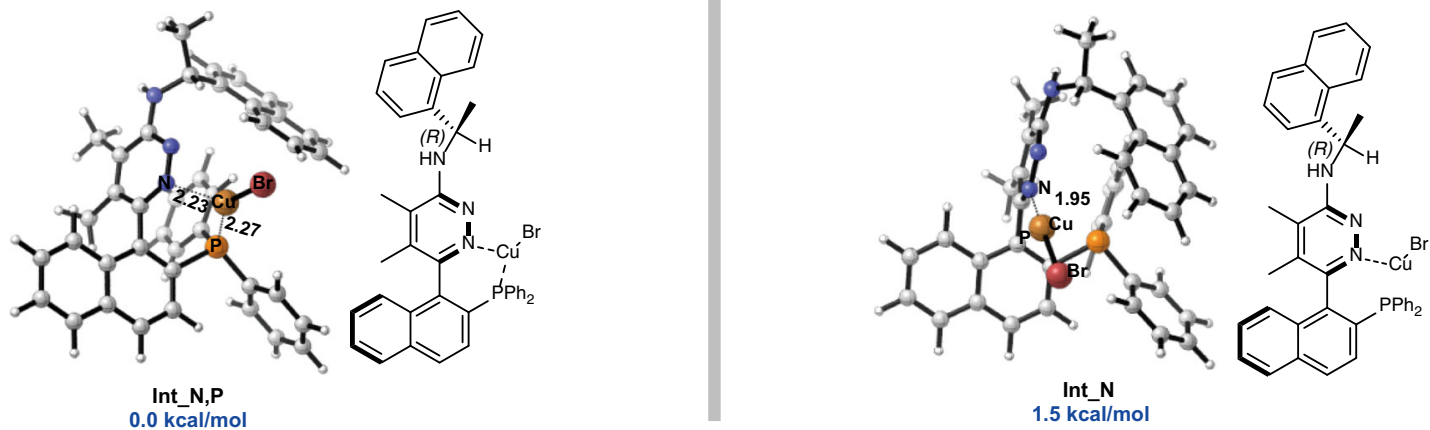

C SAESI-MS studies
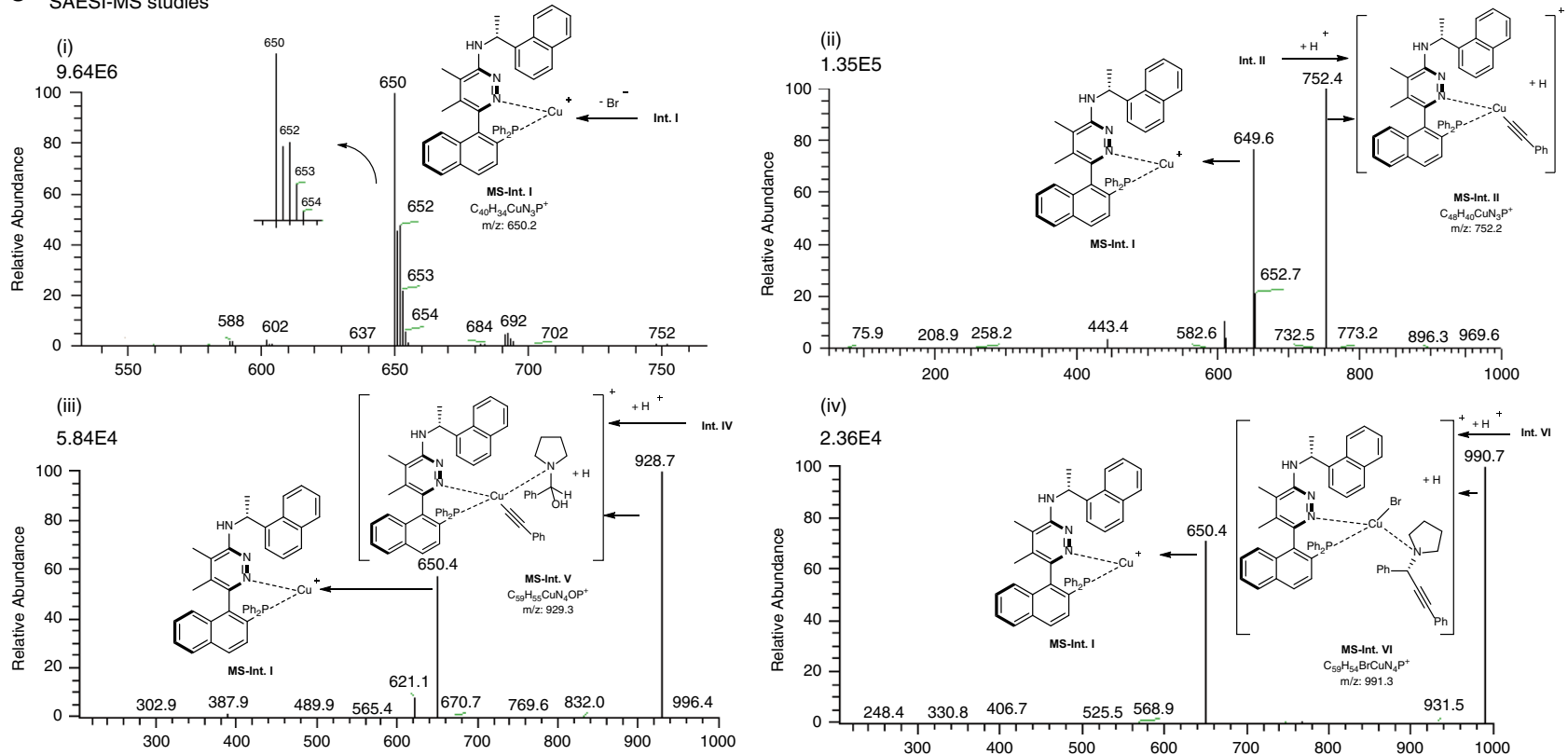

Fig. 5 Studies on reaction mechanism. a The linear effect. $\mathbf{b}$ DFT calculations on the stability of two coordination modes. The calculations were performed at the M06/SDD-6-311++G(2d,p)/SMD(toluene)//M06/LANL2DZ-6-31G(d,p) level of theory at $273.15 \mathrm{~K}$. The free energies $\Delta G$ are given with respect of Int_N,P. Bond lengths are given in angstroms. c SAESI-MS studies. (i) Expanded SAESI-MS spectrum showing the signal from $m / z$ 540-760. (ii) SAESIMS/MS spectrum showing the signal of MS-Int. II at $m / z$ 752. (iii) SAESI-MS/MS spectrum showing the signal of MS-Int. V at $m / z$ 929. (iv) SAESI-MS/ MS spectrum showing the signal of MS-Int. VI at $\mathrm{m} / z 991$.

producing $(R)$-4vyi in $98 \%$ yields and $95 \%$ ee within $48 \mathrm{~h}$. Followed by $\mathrm{Pd} / \mathrm{C}$-catalyzed hydrogenation/debenzylation and acetylation, the key intermediate (S)-5 was furnished in $81 \%$ yield and $94 \%$ ee. Finally, after intramolecular oxidative coupling of $(S)-5,(S)-(-)-N$-acetylcolchinol $(S)-6$ was obtained in $50 \%$ yield and $95 \%$ ee $(47 \%$ yield and $97 \%$ ee after recrystallization from $\mathrm{MeOH} / \mathrm{H}_{2} \mathrm{O} ;[\alpha]_{\mathrm{D}}^{27}=-37.5\left(c=0.99, \mathrm{CHCl}_{3}\right)$, reported value: $94 \%$ ee, $[\alpha]_{\mathrm{D}}^{27}=-34.0\left(c=1, \mathrm{CHCl}_{3}\right)^{56} ;[\alpha]_{\mathrm{D}}^{20}=$ $-55.8\left(c=0.135, \mathrm{CHCl}_{3}\right)^{57}$.
As stated in the introduction, the unique structure of chiral propargylic amine offers opportunities for further synthetic elaboration for the asymmetric syntheses of different amines (Fig. 4c): partial reduction of the $\mathrm{C} \equiv \mathrm{C}$ triple bond in $(S)-4 a a a$ using "P-2 nickel" in the presence of ethylenediamine or $\mathrm{LiAlH}_{4}$ provided highly selectively $(R, Z)-7$ and $(R, E)-7$ in excellent yields and $e^{59,60}$; the Mitsunobu reaction ${ }^{61}$ of $(S)$-4aaa with phthalimide afforded 1,4-butynyl diamine $(S)-8$ in $74 \%$ yield and $91 \%$ ee; primary a-allenols $(R)-\mathbf{9}$ may also be prepared with $75 \%$ yield and 
94\% ee by TBS protection, $\mathrm{ZnI}_{2}$-mediated allenation reaction, and deprotection $^{62,63}$.

Mechanistic studies. It has been reported that Quinap demonstrated a strong positive nonlinear effect ${ }^{16}$, while a weak positive nonlinear effect was observed for StackPhos (see the Supplementary information file of ref. ${ }^{27}$ ). Interestingly, a perfect linear effect was observed between the enantiopurity of $\left(R, R_{\mathrm{a}}\right)-\mathbf{L} \mathbf{2}$ and product $(S)$-4aqa for the current reaction shown in Fig. 5a, which indicated that the catalytically active species most likely involves a monomeric copper(I) complex bearing a single chiral ligand. In order to acquire more information of the catalyst species in this reaction, we tried to isolate the $\mathrm{Cu}(\mathrm{I})-\left(R, R_{\mathrm{a}}\right)-\mathbf{L} 2$ complex $^{64}$, but failed. We then performed ${ }^{31} \mathrm{P}-\mathrm{NMR}$ experiment to probe the coordination of $\mathrm{CuBr}$ with $\left(R, R_{\mathrm{a}}\right)-\mathbf{L} 2$ in $d_{6}$-toluene. A broad resonance at $\delta=-4.7$ p.p.m. was observed in the ${ }^{31} \mathrm{P}-\mathrm{NMR}$ spectrum of the resulting mixture, while the resonance at $\delta=$ -12.7 p.p.m. corresponding to the free ligand $\left(R, R_{\mathrm{a}}\right)-\mathbf{L} 2$ disappeared (for the details on ${ }^{31} \mathrm{P}-\mathrm{NMR}$ experiment, see Supplementary Figs. 5 and 6 ). The reported ${ }^{31} \mathrm{P}-\mathrm{NMR}$ chemical shifts for 1,3-bis(diphenylphosphanyl)propane (dppp) and [Cu(dppp) $\left.)_{2}\right]$ $\mathrm{BF}_{4}$ are $\delta=-17.2$ p.p.m. and $\delta=-8.5$ p.p.m., respectively 65 . The change in ${ }^{31} \mathrm{P}-\mathrm{NMR}$ chemical shift suggested that the $\mathrm{P}$ atom should coordinate to the $\mathrm{Cu}(\mathrm{I})$ atom in the solution, but may not be as strong as in the reported case. Moreover, DFT calculations were carried out to investigate the stability of two coordination modes: N,P-coordinated intermediate Int_N,P and Ncoordinated intermediate Int_N (Fig. 5c, see Supplementary information, pp 87-92 for the detailed information of computational methods). The calculated results showed that Int_N,P was more stable than Int_N by $1.5 \mathrm{kcal} / \mathrm{mol}$.

Solvent-assisted electrospray ionization mass spectrometric experiment (SAESI-MS) was further applied to unveil the nature of catalytically active species in this reaction ${ }^{66}$. First, a solution of $\mathrm{CuBr}(6.25 \mu \mathrm{mol}),\left(R, R_{\mathrm{a}}\right)-\mathbf{L} 2(6.88 \mu \mathrm{mol})$, and alkyne 1d $(0.25$ mmol) in toluene $(1 \mathrm{~mL})$ was stirred at r.t. under Ar atmosphere. After $10 \mathrm{~min}$, a signal with $\mathrm{m} / z$ of 650 , which matched the $\mathrm{m} / z$ of mono-ligated species $\left[\mathrm{Cu}\left(\left(R, R_{\mathrm{a}}\right)-\mathbf{L 2}\right)\right]^{+}$(MS-Int. I, Fig. $5 \mathrm{c}(\mathrm{i})$, calcd for $\left.\mathrm{C}_{40} \mathrm{H}_{34}{ }^{63} \mathrm{CuN}_{3} \mathrm{P}^{+}: 650.2\right)$ was observed. Meanwhile, an alkyne-coordinated intermediate MS-Int. II was confirmed by a SAESI-MS/MS experiment (Fig. 5c(ii)). Then, aldehyde 2a $(0.3$ $\mathrm{mmol})$ and pyrroline $3 \mathrm{a}(0.3 \mathrm{mmol})$ were added. The signal $\mathrm{m} / \mathrm{z}$ of 928.7 and 990.7 were attributed to mono-ligated intermediates MS-Int. V (Fig. $5 c$ (iii), calcd for $\mathrm{C}_{59} \mathrm{H}_{55}{ }^{63} \mathrm{CuN}_{4} \mathrm{OP}^{+}: 929.3$ ) and MS-Int. VI (Fig. $5 \mathrm{c}$ (iv), calcd for $\mathrm{C}_{59} \mathrm{H}_{54}{ }^{79} \mathrm{Br}^{63} \mathrm{CuN}_{4} \mathrm{P}^{+}$: 991.3), respectively. Their identities were further confirmed by the SAESI-MS/MS experiment (for details on MS study, see Supplementary Figs. 7-14).

Based on these experimental data, we proposed a mechanism shown in Fig. 6: the mono-ligated Int. I would interact with the terminal alkyne 1d to generate Int. II, in which the chiral amine in the ligand may act as a proton shuttle. The reaction of amine with aldehyde generated Int. III, which would coordinate with the $\mathrm{Cu}$ atom in Int. II to form Int. IV. $\mathrm{H}^{+}$-mediated elimination of water formed the iminium species in Int. V. Enantioselective 1,2 -addition would afford Int. VI ( $R e$ face attack is more favored), which underwent disassociation to release the productpropargylic amine $(S)$-4daa and regenerate the catalytically active Int. I to finish the catalytic cycle.

In conclusion, we have developed axially chiral $\mathrm{P}, \mathrm{N}$-ligands Pyrinap for the highly efficient catalytic enantioselective $\mathrm{A}^{3}$ coupling reaction of readily available alkynes, aldehydes, and amines to provide a variety of chiral amine-synthesis platform molecules, chiral propargylic amines, in high yields and enantioselectivity. Compared to known ligands, the salient features of this work are: (a) a general catalytic system that could be applied to a variety of challenging substrate combinations with high enantioselectivity; (b) monomeric copper(I) complex bearing a single chiral ligand has been identified as the catalytically active species; (c) the reaction has been successfully applied to the late-stage modification of some drug molecules with the sensitive

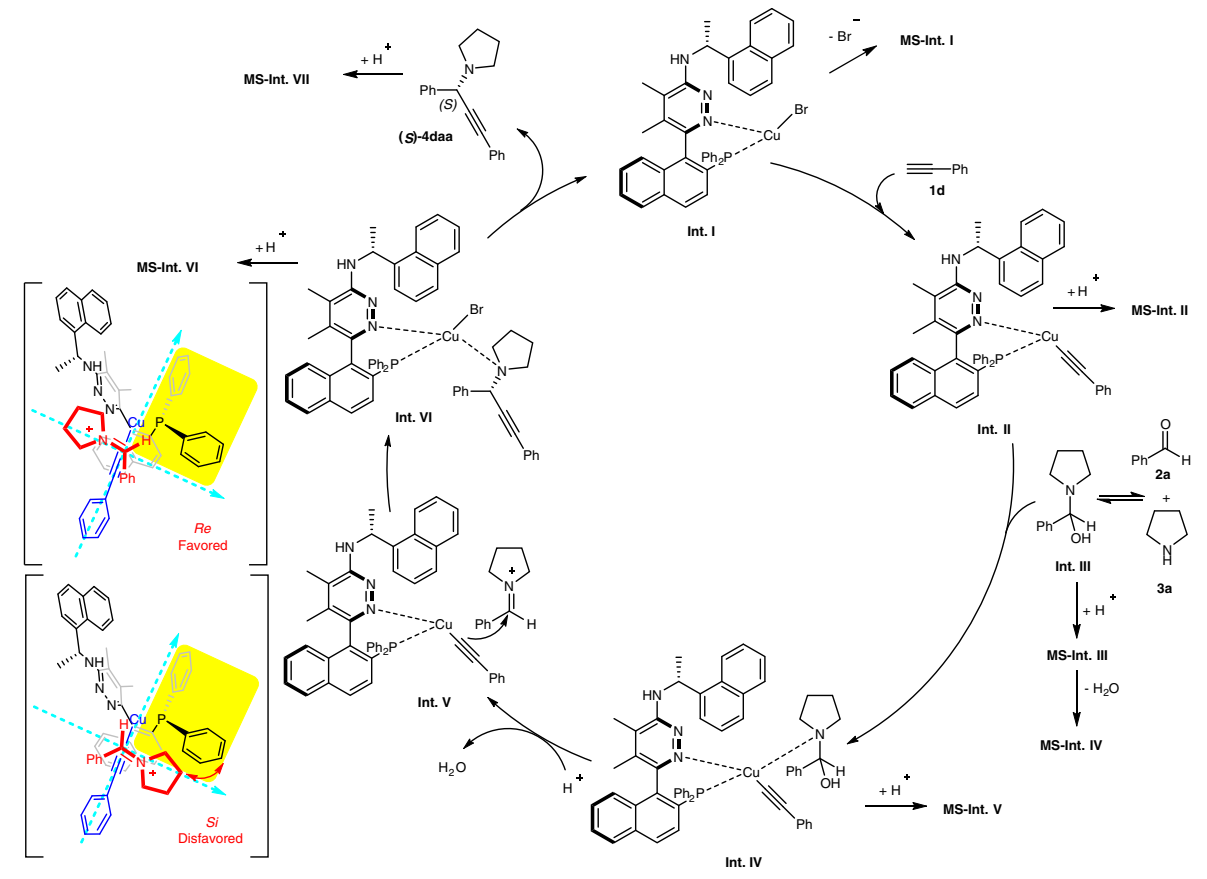

Fig. 6 A proposed mechanism of the current $\mathbf{A}^{\mathbf{3}}$-coupling reaction. A mechanism involving a monomeric copper(I) complex bearing a single chiral ligand was proposed under the instruction of the SAESI-MS studies. 
functionalities survived; (d) synthetic potential has further been demonstrated by enantioselective synthesis of (S)-(-)-N-acetylcolchinol in four steps. Further studies on applications of Pyrinap and the development of diphenyl-type ligand Pyriphen $\mathbf{L} 3$ are being actively pursued in this laboratory.

\section{Methods}

General procedure for the catalytic enantioselective $\mathbf{A}^{3}$-coupling reaction. To a flame-dried Schlenk tube were added $\mathrm{CuBr}(1.8 \mathrm{mg}, 0.0125 \mathrm{mmol}),\left(R, R_{\mathrm{a}}\right)-\mathbf{L} 2(8.1$ $\mathrm{mg}, 0.01375 \mathrm{mmol}), 4 \AA$ molecular sieves $(150.5 \mathrm{mg})$, and toluene $(0.75 \mathrm{~mL})$ sequentially under $\mathrm{Ar}$ atmosphere. After being stirred at room temperature for 30 min, 1a $(28.0 \mathrm{mg}, 0.5 \mathrm{mmol})$ and $2 \mathrm{a}(63.7 \mathrm{mg}, 0.6 \mathrm{mmol}) /$ toluene $(0.5 \mathrm{~mL})$ were added sequentially under Ar atmosphere. The resulting mixture was stirred at $0{ }^{\circ} \mathrm{C}$ for another $10 \mathrm{~min}$, followed by the addition of pyrrolidine $3 \mathrm{a}(42.7 \mathrm{mg}, 0.6 \mathrm{mmol})$. After being stirred at $0{ }^{\circ} \mathrm{C}$ for $24 \mathrm{~h}$, the reaction was complete as monitored by thin layer chromatography. The resulting mixture was filtrated through a short pad of basic aluminum oxide (200-300 mesh) eluted with dichloromethane/MeOH $(10: 1,44 \mathrm{~mL})$. After evaporation, the residue was purified by chromatography on silica gel (eluent: petroleum ether/ethyl acetate $=2: 1)$ to afford $(S)-4 a a a(74.9 \mathrm{mg}$ $70 \%$ ) as a liquid: $90 \%$ ee (high-performance liquid chromatography conditions: Chiralcel OD-H column, hexane $/ i-\mathrm{PrOH}=95 / 5,1.2 \mathrm{~mL} / \mathrm{min}, \lambda=214 \mathrm{~nm}, t_{\mathrm{R}}(\mathrm{ma}-$ jor $\left.)=10.1 \mathrm{~min}, t_{\mathrm{R}}(\operatorname{minor})=7.7 \mathrm{~min}\right) ;[\alpha]_{\mathrm{D}}^{31}=-28.1\left(c=1.05, \mathrm{CHCl}_{3}\right) ;{ }^{1} \mathrm{H} \mathrm{NMR}$ $\left(400 \mathrm{MHz}, \mathrm{CDCl}_{3}\right) \delta 7.51(\mathrm{~d}, J=7.2 \mathrm{~Hz}, 2 \mathrm{H}, \mathrm{ArH}), 7.33(\mathrm{t}, J=7.2 \mathrm{~Hz}, 2 \mathrm{H}, \mathrm{ArH})$, $7.27(\mathrm{t}, J=6.4 \mathrm{~Hz}, 1 \mathrm{H}, \mathrm{ArH}), 4.62(\mathrm{~s}, 1 \mathrm{H}, \mathrm{CH}), 4.36\left(\mathrm{~d}, J=1.6 \mathrm{~Hz}, 2 \mathrm{H}, \mathrm{OCH}_{2}\right)$, 2.67-2.51 (m, 4H, $\left.2 \times \mathrm{NCH}_{2}\right), 2.04(\mathrm{~s}, 1 \mathrm{H}, \mathrm{OH}), 1.83-1.71\left(\mathrm{~m}, 4 \mathrm{H}, 2 \times \mathrm{CH}_{2}\right) ;{ }^{13} \mathrm{C}$ NMR $\left(100 \mathrm{MHz}, \mathrm{CDCl}_{3}\right) \delta 138.9,128.24,128.21,127.7,85.0,82.7,58.9,50.9,50.5$, 23.2; MS (EI) $m / z(\%) 215$ (M+, 20.49), 138 (100); IR (neat): $v=3065,2960,2924$ $2871,2841,2729,1489,1455,1372,1345,1309,1270,1233,1206,1121,1087,1074$, $1033,1024 \mathrm{~cm}^{-1}$; HRMS calcd for $\mathrm{C}_{14} \mathrm{H}_{18} \mathrm{NO}\left([\mathrm{M}+\mathrm{H}]^{+}\right): 216.1383$, found: 216.1381.

\section{Data availability}

All data that support the findings of this study are available in the online version of this paper in the accompanying Supplementary information (including experimental procedures, compound characterization data, and spectra)

The X-ray crystallographic coordinates for structures of $\left(R, S_{\mathrm{a}}\right)-N$-Ph-Pyrinap and $(R$, $\left.S_{\mathrm{a}}\right)-N$-Nap-Pyrinap reported in this Article have been deposited at the Cambridge Crystallographic Data Centre (CCDC) under deposition numbers CCDC $1911487((R$, $\left.S_{\mathrm{a}}\right)-\mathrm{N}$-Ph-Pyrinap) and $1911488\left(\left(R, S_{\mathrm{a}}\right)-\mathrm{N}\right.$-Nap-Pyrinap). These data can be obtained free of charge from http://www.ccdc.cam.ac.uk/data_request/cif.

Received: 28 May 2020; Accepted: 16 November 2020;

Published online: 04 January 2021

\section{References}

1. Reynolds, T. Hemlock alkaloids from socrates to poison aloes. Phytochemistry 66, 1399-1406 (2005).

2. Rodgman, A. \& Perfetti, T. A. The Chemical Components of Tobacco and Tobacco Smoke 2nd edn (CRC Press, 2013).

3. Zhang, Q., Tu, G., Zhao, Y. \& Cheng, T. Novel bioactive isoquinoline alkaloids from Carduus crispus. Tetrahedron 58, 6795-6798 (2002).

4. Blaser, H.-U. The chiral switch of (S)-metolachlor: a personal account of an industrial odyssey in asymmetric catalysis. Adv. Synth. Catal. 344, 17-31 (2002).

5. Hirota, Y., Sugiura, H., Kuroda, N., Wada, T. \& Tsujimoto, K. Imidazole derivatives, bactericides containing them, and process for their preparation. Patent EP0248086B1 (1985).

6. Oldfield, V., Keating, G. M. \& Perry, C. M. Rasagiline. Drugs 67, 1725-1747 (2007).

7. Corbett, J. W. et al. Expanded-spectrum nonnucleoside reverse transcriptase inhibitors inhibit clinically relevant mutant variants of human immunodeficiency virus type 1. Antimicrob. Agents Chemother. 43, 2893-2897 (1999).

8. Aladesanmi, A. J., Kelley, C. J. \& Leary, J. D. The constituents of dysoxylum lenticellare. I. Phenylethylisoquinoline, homoerythrina, and dibenzazecine alkaloids. J. Nat. Prod. 46, 127-131 (1983).

9. Sitnikov, N. S. \& Fedorov, A. Y. Synthesis of allocolchicinoids: a 50 year journey. Russ. Chem. Rev. 82, 393-411 (2013).

10. Nugent, T. C. Chiral Amine Synthesis: Methods, Developments and Applications (Wiley, Weinheim, 2010).

11. Li, W. \& Zhang, X. Stereoselective Formation of Amines (Springer, Heidelberg, 2014).
12. Lauder, K., Toscani, A., Scalacci, N. \& Castagnolo, D. Synthesis and reactivity of propargylamines in organic chemistry. Chem. Rev. 117, 14091-14200 (2017).

13. Peshkov, V. A., Pereshivko, O. P. \& Van der Eycken, E. V. A walk around the $\mathrm{A}^{3}$-coupling. Chem. Soc. Rev. 41, 3790-3807 (2012).

14. Rokade, B. V., Barker, J. \& Guiry, P. J. Development of and recent advances in asymmetric A3 coupling. Chem. Soc. Rev. 48, 4766-4790 (2019).

15. Alcock, N. W., Brown, J. M. \& Hulmes, D. I. Synthesis and resolution of 1-(2diphenylphosphino-1-naphthyl)isoquinoline; a P-N chelating ligand for asymmetric catalysis. Tetrahedron: Asymmetry 4, 743-756 (1993).

16. Gommermann, N., Koradin, C., Polborn, K. \& Knochel, P. Enantioselective, copper(I)-catalyzed three-component reaction for the preparation of propargylamines. Angew. Chem. Int. Ed. 42, 5763-5766 (2003).

17. Dube, H., Gommermann, N. \& Knochel, P. Synthesis of chiral aaminoalkylpyrimidines using an enantioselective three-component reaction. Synthesis 2015-2025 (2004).

18. Gommermann, N. \& Knochel, P. Practical highly enantioselective synthesis of terminal propargylamines. An expeditious synthesis of $(S)-(+)$-coniine. Chem. Commun. 2324-2325 (2004).

19. Gommermann, N. \& Knochel, P. 2-Phenallyl as a versatile protecting group for the asymmetric one-pot three-component synthesis of propargylamines. Chem. Commun. 4175-4177 (2005).

20. Gommermann, N. \& Knochel, P. Highly enantioselective synthesis of propargylamines using (mesitylmethyl)benzylamine. Synlett 2005, 2799-2801 (2005).

21. Gommermann, N. \& Knochel, P. Preparation of functionalized primary chiral amines and amides via an enantioselective three-component synthesis of propargylamines. Tetrahedron 61, 11418-11426 (2005).

22. Gommermann, N. \& Knochel, P. Practical highly enantioselective synthesis of propargylamines through a copper-catalyzed one-pot three-component condensation reaction. Chem. Eur. J. 12, 4380-4392 (2006).

23. Gommermann, N. \& Knochel, P. N,N-dibenzyl- $N$-[1-cyclohexyl-3(trimethylsilyl)-2-propynyl]-amine from cyclohexanecarbaldehyde, trimethylsilylacetylene and dibenzylamine. Org. Synth. 84, 1-10 (2007).

24. Knöpfel, T. F., Aschwanden, P., Ichikawa, T., Watanabe, T. \& Carreira, E. M Readily available biaryl P,N ligands for asymmetric catalysis. Angew. Chem. Int. Ed. 43, 5971-5973 (2004).

25. Aschwanden, P., Stephenson, C. R. J. \& Carreira, E. M. Highly enantioselective access to primary propargylamines: 4-piperidinone as a convenient protecting group. Org. Lett. 8, 2437-2440 (2006).

26. Cardoso, F. S. P., Abboud, K. A. \& Aponick, A. Design, preparation, and implementation of an imidazole-based chiral biaryl P,N-ligand for asymmetric catalysis. J. Am. Chem. Soc. 135, 14548-14551 (2013).

27. Paioti, P. H. S., Abboud, K. A. \& Aponick, A. Catalytic enantioselective synthesis of amino skipped diynes. J. Am. Chem. Soc. 138, 2150-2153 (2016).

28. Paioti, P. H. S., Abboud, K. A. \& Aponick, A. Incorporation of axial chirality into phosphino-imidazoline ligands for enantioselective catalysis. ACS Catal. 7, 2133-2138 (2017).

29. Naeimi, H. \& Moradian, M. Thioether-based copper(I) schiff base complex as a catalyst for a direct and asymmetric $\mathrm{A}^{3}$-coupling reaction. Tetrahedron: Asymmetry 25, 429-434 (2014).

30. Zhao, C. \& Seidel, D. Diastereofacial $\pi$-stacking as an approach to access an axially chiral P,N-ligand for asymmetric catalysis. J. Am. Chem. Soc. 137, 4650-4653 (2015).

31. Rokade, B. V. \& Guiry, P. J. Diastereofacial $\pi$-stacking as an approach to access an axially chiral P,N-ligand for asymmetric catalysis. ACS Catal. 7, 2334-2338 (2017)

32. Rokade, B. V. \& Guiry, P. J. Enantioselective catalytic asymmetric A3 coupling with phosphino-imidazoline ligands. J. Org. Chem. 84, 5763-5772 (2019).

33. Miyashita, A. et al. Synthesis of $2,2^{\prime}$-bis(diphenylphosphino)-1,1'-binaphthyl (BINAP), an atropisomeric chiral bis(triaryl)phosphine, and its use in the rhodium(I)-catalyzed asymmetric hydrogenation of $\alpha$-(acylamino)acrylic acids. J. Am. Chem. Soc. 102, 7932-7934 (1980).

34. Schmid, R., Foricher, J., Cereghetti, M. \& Schönholzer, P. Axially dissymmetric diphosphines in the biphenyl series: synthesis of $\left(6,6^{\prime}\right.$ dimethoxybiphenyl-2,2'-diyl)bis(diphenylphosphine)('Meo-BIPHEP') and analogues via an ortho-lithiation/iodination Ullmann-reaction approach. Helv. Chim. Acta 74, 370-389 (1991)

35. Genêt, J. P. et al. Enantioselective hydrogenation reactions with a full set of preformed and prepared in situ chiral diphosphine-ruthenium (II) catalysts. Tetrahedron: Asymmetry 5, 675-690 (1994).

36. Saito, T. et al. New chiral diphosphine ligands designed to have a narrow dihedral angle in the biaryl backbone. Adv. Synth. Catal. 343, 264-267 (2001).

37. Michaud, G., Bulliard, M., Ricard, L., Genêt, J.-P. \& Marinetti, A. A strategy for the stereoselective synthesis of unsymmetric atropisomeric ligands: preparation of NAPhePHOS, a new biaryl diphosphine. Chem. Eur. J. 8, 3327-3330 (2002). 
38. Madec, J., Michaud, G., Genêt, J.-P. \& Marinetti, A. New developments in the synthesis of heterotopic atropisomeric diphosphines via diastereoselective aryl coupling reactions. Tetrahedron: Asymmetry 15, 2253-2261 (2004).

39. Abdur-rashid, K. et al. Biaryl diphosphine ligands, intermediates of the same and their use in asymmetric catalysis. Patent WO2012/31358 (2012).

40. Rokade, B. V. \& Guiry, P. J. Axially chiral P,N-ligands: some recent twists and turns. ACS Catal. 8, 624-643 (2017).

41. Fujimori, S. et al. Stereoselective conjugate addition reactions using in situ metallated terminal alkynes and the development of novel chiral P,N-ligands. Bull. Chem. Soc. Jpn 80, 1635-1657 (2007).

42. Fan, W. \& Ma, S. An easily removable stereo-dictating group for enantioselective synthesis of propargylic amines. Chem. Commun. 49, 10175-10177 (2013).

43. Xu, D., Li, Z. \& Ma, S. Novozym-435-catalyzed enzymatic separation of racemic propargylic alcohols. A facile route to optically active terminal aryl propargylic alcohols. Tetrahedron Lett. 44, 6343-6346 (2003).

44. Santandrea, J., Minozzi, C., Cruché, C. \& Collins, S. K. Photochemical dualcatalytic synthesis of alkynyl sulfides. Angew. Chem. Int. Ed. 56, 12255-12259 (2017).

45. Marras, G., Rasparini, M., Tufaro, R., Castaldi, G. \& Ghisleri, D. A process for the preparation of $(R)$-1-aminoindanes. Patent WO2010/49379 (2010).

46. China Cooperative Research Group on Qinghaosu and Its Derivatives as Antimalarials. Chemical studies on qinghaosu (artemisinine). J. Tradit. Chin. Med. 2, 3-8 (1982).

47. Davis, P. D. et al. ZD6126: a novel vascular-targeting agent that causes selective destruction of tumor vasculature. Cancer Res. 62, 7247-7253 (2002).

48. Bergemann, S. et al. Novel B-ring modified allocolchicinoids of the NCME series: Design, synthesis, antimicrotubule activity and cytotoxicity. Bioorg. Med. Chem. 11, 1269-1281 (2003).

49. Micheletti, G. et al. Vascular-targeting activity of ZD6126, a novel tubulinbinding agent. Cancer Res. 63, 1534-1537 (2003).

50. Čech, J. \& Šantavý, F. The effect of hydrogen peroxide in alkaline medium on colchiceine. Collect. Czech. Chem. Commun. 14, 532-539 (1949).

51. Fernholz, H. Über die umlagerung des colchicins mit natriumalkoholat und die struktur des ringes C. Justus Liebigs Ann. Chem. 568, 63-72 (1950).

52. Sawyer, J. S. \& Macdonald, T. L. Total synthesis of $( \pm)-\mathrm{N}$-acetylcolchinol. Tetrahedron Lett. 29, 4839-4842 (1988).

53. Besong, G., Jarowicki, K., Kocienski, P. J., Sliwinski, E. \& Boyle, F. T. Synthesis of $(S)-(-)-N$-acetylcolchinol using intramolecular biaryl oxidative coupling. Org. Biomol. Chem. 4, 2193-2207 (2006).

54. Wu, T. R. \& Chong, J. M. Asymmetric synthesis of propargylamides via 3,3'disubstituted binaphthol-modified alkynylboronates. Org. Lett. 8, 15-18 (2006).

55. Broady, S. D., Golden, M. D., Leonard, J., Muir, J. C. \& Maudet, M. Asymmetric synthesis of $(S)-(-)-N$-acetylcolchinol via ullmann biaryl coupling. Tetrahedron Lett. 48, 4627-4630 (2007).

56. Besong, G. et al. A synthesis of $(\mathrm{a} R, 7 S)-(-)-N$-acetylcolchinol and its conjugate with a cyclic RGD peptide. Tetrahedron 64, 4700-4710 (2008).

57. Nicolaus, N. et al. A convenient entry to new C-7-modified colchicinoids through azide alkyne [3+2] cycloaddition: application of ring-contractive rearrangements. Heterocycles 82, 1585-1600 (2010).

58. Shchegravina, E., Svirshchevskaya, E., Schmalz, H.-G. \& Fedorov, A. A facile synthetic approach to nonracemic substituted pyrrolo-allocolchicinoids starting from natural colchicine. Synthesis 51, 1611-1622 (2018).

59. Brown, C. A. \& Ahuja, V. K. "P-2 nickel" catalyst with ethylenediamine, a novel system for highly stereospecific reduction of alkynes to cis-olefins. J. Chem. Soc. Chem. Commun. 553-554 (1973).

60. Courtois, G. \& Miginiac, P. Action d'organométalliques fonctionnels sur les gem-aminoéthers et les sels d'immonium. II. Synthèse d'amines $\gamma$ fonctionnelles $\alpha$-acétyléniques, $\alpha$-éthyléniques $Z$ ou $E$ et saturées. Bull. Soc. Chim. Fr. 2, 21-27 (1983).

61. Mitsunobu, O. \& Yamada, M. Preparation of esters of carboxylic and phosphoric acid via quaternary phosphonium salts. Bull. Chem. Soc. Jpn 40, 2380-2382 (1967).
62. Ye, J., Fan, W. \& Ma, S. tert-Butyldimethylsilyl-directed highly enantioselective approach to axially chiral a-allenols. Chem. Eur. J. 19, 716-720 (2013)

63. Ye, J. \& Ma, S. Preparation of (R)-4-cyclohexyl-2,3-butadien-1-ol. Org. Synth. 91, 233-247 (2014).

64. Koradin, C., Polborn, K. \& Knochel, P. Enantioselective synthesis of propargylamines by copper-catalyzed addition of alkynes to enamines. Angew. Chem. Int. Ed. 41, 2535-2538 (2002).

65. Comba, P., Katsichtis, C., Nuber, B. \& Pritzkow, H. Solid-state and solution structural properties of copper(I) compounds with bidentate phosphane ligands. Eur. J. Inorg. Chem. 1999, 777-783 (1999).

66. Zhang, J.-T., Wang, H.-Y., Zhu, W., Cai, T.-T. \& Guo, Y.-L. Solvent-assisted electrospray ionization for direct analysis of various compounds (complex) from low/nonpolar solvents and eluents. Anal. Chem. 86, 8937-8942 (2014).

\section{Acknowledgements}

Financial support from National Science Foundation of China Program (21690063) is greatly appreciated. We thank Mr. Yuchen Zhang in this group for reproducing the syntheses of $(S)$-4aia and (S)-4lwi in Fig. 3 presented in the text, and we thank Mr. WeiFeng Zheng in this group for providing the aldehyde $\left(R_{\mathrm{a}}\right)-\mathbf{2 m}$.

\section{Author contributions}

S.M. directed the research and developed the concept of the reaction with Q.L. and H.X. who also performed the experiments and prepared the Supplementary Information. Q.L. and H.X. contributed equally to this work. Y.G. directed the SAESI-MS reaction with Y.L., who also collected and analyzed the SAESI-MS spectra data. X.Z. and Y.Y. performed the computational studies. Q.L., H.X., and S.M. checked the experimental data. Q.L. and S.M. wrote the manuscript with contributions from the other authors.

\section{Competing interests}

The authors declare no competing interests.

\section{Additional information}

Supplementary information is available for this paper at https://doi.org/10.1038/s41467020-20205-0.

Correspondence and requests for materials should be addressed to S.M.

Peer review information Nature Communications thanks the anonymous reviewers for their contribution to the peer review of this work.

Reprints and permission information is available at http://www.nature.com/reprints

Publisher's note Springer Nature remains neutral with regard to jurisdictional claims in published maps and institutional affiliations.

Open Access This article is licensed under a Creative Commons Attribution 4.0 International License, which permits use, sharing, adaptation, distribution and reproduction in any medium or format, as long as you give appropriate credit to the original author(s) and the source, provide a link to the Creative Commons license, and indicate if changes were made. The images or other third party material in this article are included in the article's Creative Commons license, unless indicated otherwise in a credit line to the material. If material is not included in the article's Creative Commons license and your intended use is not permitted by statutory regulation or exceeds the permitted use, you will need to obtain permission directly from the copyright holder. To view a copy of this license, visit http://creativecommons.org/ licenses/by/4.0/.

(C) The Author(s) 2021 